\title{
Point-of-consumption interventions to promote virtuous food choices of tourists with self-benefit or other-benefit appeals: a randomised field experiment
}

\section{Claudia Cozzio, Michael Volgger \& Ross Taplin}

To cite this article: Claudia Cozzio, Michael Volgger \& Ross Taplin (2021): Point-ofconsumption interventions to promote virtuous food choices of tourists with self-benefit or other-benefit appeals: a randomised field experiment, Journal of Sustainable Tourism, DOI: 10.1080/09669582.2021.1932936

To link to this article: https://doi.org/10.1080/09669582.2021.1932936

央 Published online: 02 Jun 2021.

Submit your article to this journal $₫$

Llll Article views: 317

Q View related articles $\sqsubset$

View Crossmark data \lceil 


\title{
Point-of-consumption interventions to promote virtuous food choices of tourists with self-benefit or other-benefit appeals: a randomised field experiment
}

\author{
Claudia Cozzio ${ }^{a}$ (D), Michael Volgger ${ }^{b, c}$ and Ross Taplin ${ }^{d}$

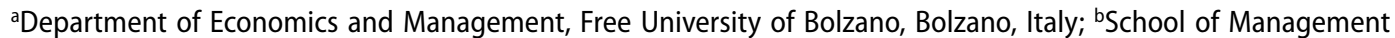 \\ and Marketing (Tourism Research Cluster), Faculty of Business and Law, Curtin University, Perth, Australia; \\ 'Catholic University of Eichstätt-Ingolstadt, Germany; ${ }^{\mathrm{d} S c h o o l}$ of Economics, Finance and Property (Tourism \\ Research Cluster), Faculty of Business and Law, Curtin University, Perth, Australia
}

\begin{abstract}
There is very limited research on point-of-consumption/point-of-purchase interventions to promote more ecological and healthier food choices among tourists. To fill this gap, this paper analyses the impact of different factual appeals including information about taste (placebo), nutrients, carbon footprints and distance of transportation on food choices of tourists at hotel salad buffets. The research pursued a randomised field experiment in two Italian hotels adopting a $4 \times 2$ between-group experimental design (appeal content $X$ endorsement). In addition to measuring the actual consumption of salad vegetables by weighting, a short survey was administered on 329 tourists. By comparing effectiveness of persuasion along a continuum of self-benefit vs other-benefit appeals, this experiment finds a higher effectiveness of pure self-benefit appeals stressing healthiness or mixed self/other-benefits stressing local origin, compared to other-benefits that focus on ecological friendliness. These findings are in line with the idea that egoistic and selfish-altruistic motivations dominate in tourism consumption over mere altruistic motivations.
\end{abstract}

\section{ARTICLE HISTORY}

Received 9 February

2021

Accepted 17 May 2021

\section{KEYWORDS}

Food choice;

health;

carbon footprint;

local food;

hotel;

endorsement

\section{Introduction}

Food is not only an essential element of the tourism experience but also a critical factor in determining sustainability implications of tourism; it also impacts on the wellbeing and health of tourists (Bertella, 2020; Moskwa et al., 2015). Therefore, it is critical to understand how consumers' food choices while on holidays can be influenced. Existing research indicates that the consumption and purchase environment have a strong influence on consumption choices (Inman \& Winer, 1998). More specifically, point-of-consumption/point-of-purchase interventions demonstrated capability to change food consumption in tourism (Cozzio et al., 2020; Dolnicar et al., 2020) as well as in non-tourism contexts (Milliron et al., 2012; Newman et al., 2016).

One of the simplest and most "low-intensity" ways of environmental manipulation at the point-of-consumption/point-of-purchase is the provisioning of information (Hardeman et al., 2000). However, research analysing how provisioning of information can influence tourist

CONTACT Claudia Cozzio claudia.cozzio@unibz.it $\mathbf{O}$ Department of Economics and Management, Free University of Bolzano, Piazza Universitá 1, Bolzano 39100, Italy

๑) 2021 Informa UK Limited, trading as Taylor \& Francis Group 
behaviour to induce food choices with better sustainability and health outcomes is rare. For hospitality, there has been some research on nutritional labelling in restaurants (Wansink et al., 2001). Lo et al. (2017) conducted a survey that indicates restaurant patrons in Hongkong pay more attention to nutritional information rather than to sustainability information. Research also supports the possibility to nudge tourists to consume particular foodstuff through menu stimuli highlighting local origin and organic production (Cozzio et al., 2020; see also Shafieizadeh \& Tao, 2020). Despite this initial work, there is a need to clarify further which type of fact-based information is more effective in influencing tourists' food selection in hotels (for a general discussion of research gaps in sustainability marketing see also Villarino \& Font, 2015). In particular, we are not aware of prior research that analyses and compares the effects of offering different types of factual information (such as nutrition information, carbon footprints and distance of transportation) on tourists' food choices in hotels.

According to the dual process theory (Kahneman, 2011), people process information mentally through one out of two systems: system 1 entailing fast-and-frugal heuristics focussed on fluent cues (such as appearance), and system 2 involving more deliberate processing and extensive consideration of the provided information. Detailed and numerical information, as the one used in the factual interventions in this study, tends to be associated with system 2 (Sanjari et al., 2017). Generally, but in particular in system 2 processing, information is more likely to be impactful if there is a congruence with consumers' motivations (Moorman \& Matulich, 1993) and goals (Van Herpen \& Van Trijp, 2011). Tourism is believed to be a "non-essential, hedonic, aspirational consumption activity" (Font \& McCabe, 2017, p. 870) where "pure" altruism is rare, while egoism and a blended form of selfish altruism dominate (Miller, 2003). Even "[e]thical tourism is a pleasure-seeking activity" (Malone et al., 2014, p. 252). This research is designed to extend knowledge on the effectiveness of behaviour-inducing factual appeals that target the collective versus the individual level into the food and tourism space. Following White and Peloza (2009), these appeals may be called self-benefit appeals and other-benefit appeals, respectively. Regarding food consumption, short-term hedonism (self-benefit A) can be most directly translated into a taste focus (Guha et al., 2018); health and diet-goals in food choices have a strong link to rational and longer-term self-interest (self-benefit B). Caring about carbon footprints of food is most clearly altruistically driven and thus can be classified as non-hedonic other-benefit appeal. Finally, preferring local food is potentially linked to a mix of all the aforementioned motivations (Kim \& Eves, 2012) and thus will be classified as a combination of (hedonic and non-hedonic) self-benefit and other-benefit appeals.

However, as food choices at the point-of-consumption/point-of-purchase tend to be made quickly, tourists may lack the necessary attention and willingness to process more complex cues. As dual process theory suggests, some tourists may process the provided information through system 1, that is on "peripheral pathways" that lack dedication of cognitive effort but are dominated by fast-and-frugal heuristics (Petty \& Cacioppo, 1984). Therefore, this study also includes an additional layer of an easy-to-implement message endorsement by hotel general managers to induce tourists to pay more attention to the information provided at hotel buffets and push them onto system 2 elaboration. Expertise-based endorsement under high levels of congruence between product and endorsers tends to make system 2 (central route) processing more likely (Lee \& Koo, 2016).

The aim of this paper is to explore the degree to which a continuum of egoistic vs altruistic persuasive interventions in the form of factual information influence tourists in their food choices at a hotel buffet. In particular, this paper looks at the impact of messages outlining taste (a self-benefit), health-related features (more specifically nutritional information, a self-benefit), ecological impacts (more specifically carbon footprints, an other-benefit) and local origin (more specifically distance of transportation, both self- and other-benefit) on consumers' salad vegetable consumption while on holiday. In addition, this paper also examines if a 'simple' endorsement by the hotel general manager can increase the effect of providing factual messages on 
tourist behaviour. To investigate the impact of factual appeal type and endorsement on tourists' food consumption, the research implemented an unobtrusive and randomised field experiment in two Italian hotels adopting a 4 appeal contents $X 2$ endorsements between-group experimental design.

\section{Literature}

\section{Self-benefit appeals vs other-benefit appeals}

Originally studied in the context of charitable organisations as a way to encourage donations (Bendapudi et al., 1996), other-benefit and self-benefit appeals have received some attention in advertising research (White \& Peloza, 2009). Self-benefit appeals try to persuade consumers by stressing direct or indirect individual benefits derived from the engagement in a specific behaviour (e.g., highlighting money saving as a consequence of energy saving); in contrast, other-benefit appeals highlight, for example, social outcomes of behaviours (e.g., pointing out that the society at large benefits from energy saving practices) (White \& Simpson, 2013). There has been an ongoing debate regarding whether sustainable products should be promoted by either relying on altruistic messages that emphasise positive consumption implications for collective goods or by utilising self-centred messages that communicate benefits for the individual self (e.g., feeling good, monetary gains, increased status) (White \& Peloza, 2009).

Prior studies investigating effectiveness of these two appeal types in influencing consumer behaviours led to inconclusive findings (Choi \& Lee, 2020). For example, in the domain of energy conservation, Rizzi et al. (2020) found an advertisement focused on self-benefit appeals to be effective in promoting reductions in energy consumption. Yadav (2016) argued that egoistic values related to health concern (i.e., a self-benefit) outperform altruistic values associated with environmental protection in predicting intentions to buy organic food. Conversely, Jäger and Weber (2020) reported that other-benefit appeals (i.e., environmental benefits) lead to greater organic food purchase intentions compared to self-benefit appeals (i.e., health advantages). Similarly, Kareklas et al. (2014) showed that an advertisement featuring altruistic claims produces more favourable organic food purchase intentions than a message that adopts egoistic claims. For the fashion industry, Visser et al. (2015) presented evidence that in shoe advertisements the combination between self-benefit (i.e., being fashionable) and other-benefit (i.e., environmentally friendly materials) appeals increase buying intentions compared to an advertisement focused solely on either self-benefits or other-benefits.

One reason why determining which of the two appeals is more effective has proven to be challenging is likely related to the tendency of consumers to respond more positively to an appeal that is aligned with their underlying buying motives (Green \& Peloza, 2014). Hence, we can assume that goal-compatibility that stems from "the combination of the activation of the self and the appeal type will lead to the most positive sustainable consumer intentions and behaviors" (White \& Simpson, 2013, p. 80). In the context of green advertising, other-benefit appeals mainly relate to how goods are produced and distributed in an environmentally friendly way. Hence, they are more aligned with social goals embedded in altruistic values (e.g., protecting the environment for everyone's benefit), than to personal goals associated with health benefits or economic savings (Kareklas et al., 2014). While understanding consumption purposes can be a complex task (Bialkova \& van Trijp, 2011), taken together, these findings indicate that the effectiveness of an appeal type is contingent on the specific consumption goals and context (Gao et al., 2020). Hence, for this paper's research objective, it is reasonable to assume that the underlying consumption motivations in the tourism setting influence the effectiveness of interventions to induce particular food choices. 


\section{Egoism, altruism and selfish altruism in tourism}

Altruism can be defined as a range of behaviours and motives that benefit others (Wilson, 2015). It is considered to be the opposite of egoism: The normative argument often positions altruism as a morally superior attitude to egoism (Comte, 1851). It is central to note that there is a continuum of degrees to which motivations are 'truly' and ultimately altruistic or whether a combination of motivations is involved with altruism being a 'proximate' surface manifestation of fundamentally egoistic objectives (e.g., Trivers, 1985). In alignment with the mainstream in other fields, instances of "true" altruism have rarely been observed or conceptualised in the tourism context. Some pioneering work utilised the idea of reciprocal altruism, which sees altruism as being a derivative of egoism, to understand collaboration, and the lack thereof, in guest-host interactions in tourism (Fennell, 2006). Other research on altruism in tourism has focussed on volunteer tourists and their motivations (Paraskevaidis \& Andriotis, 2017). These studies suggest that host volunteers are more often driven by self-interest, whereas volunteer tourists have balanced altruistic and egoistic motivations (Lockstone-Binney et al., 2010). Marketing research also indicates that highlighting sustainability benefits alone is less effective with tourists than following mixed communication strategies that stress experiential qualities in addition to ethical features (Font \& McCabe, 2017; Hardeman et al., 2017). In sum, tourism literature depicts tourists as first and foremost hedonic consumers (Hosany \& Gilbert, 2010), which implies a high degree of pleasure-seeking, fun-orientated and multi-sensory-and ultimately ego-focussed-consumption behaviour. Existing research shows that taste and flavour are important for everyday food choices (Clark, 1998). Given the importance of (egoistic) hedonic consumption for tourism, on a basic level it can be expected that the sensory attributes of taste and flavour are even more relevant for food choices on holiday.

In addition to taste and flavour, health is another egoistically anchored key driver in human food consumption (Clark, 1998). For example, prior studies unveiled the importance of reporting nutritional information of food (Hwang \& Lorenzen, 2008; Kergoat et al., 2019). Sun (2013) showed that descriptive nutrition information significantly influences consumers' dining intentions, while reporting quantitative nutrition information has a weaker effect. Nutritional food claims attracted consumers' attention at the point of purchase resulting in increased purchase intentions (Chambault, 2016) and healthiness perceptions (Nobrega et al., 2020). There is also initial evidence supporting the idea that reporting nutritional properties of food (such as energy, fat, sugars, etc.) can influence consumption of healthy food in restaurants (Howlett et al., 2009). Some authors argued that these findings should be applicable to a tourism context as tourists do not consider food consumption only as an enjoyable sensory pleasure but they also see it as an important vehicle to achieve healthier lifestyles and higher quality of life (Johnston \& Baumann, 2014). There is limited research on the manifestation of health values on tourism behaviour in general and extremely limited research on healthy eating while on vacation more specifically. Most of the existing research concentrates on showing that sometimes tourists avoid food due to health and hygiene risks (Torres \& Skillicorn, 2004). Chang (2017) found evidence that food contents and nutrients are important to some tourists. Based on this preliminary evidence, and food consumption literature more broadly, it is reasonable to expect that health information can influence tourists' food choices.

While a persuasive effect of presenting nutritional information on tourists' food choices can be deduced from the existing literature, the effect of reporting information on environmental superiority on menus such as low levels of carbon emissions is less clear (Filimonau et al., 2017). Despite not being hedonic, health-driven food consumption can be conceived as primarily egoistically driven, making nutritional information a self-benefit appeal. In contrast, consuming food purely because of their environmental superiority can be associated with altruism. Providing information on carbon emissions to consumers thus can be classified as 
an other-benefit appeal. In line with the idea that altruism is rare in tourism, Cozzio et al. (2020) presented evidence that information on 'sustainable production' is less powerful in influencing tourists' food consumption than information on 'organic production' and 'local origin', which both combine other-benefits with self-benefits. Otherwise, there has been very limited research with strictly environmental appeals such as carbon footprints in a context of food choices while on holiday. Existing research conducted in restaurants (i.e., not necessarily in a tourism context) presents mixed findings. Some studies indicated that displaying information on environmental superiority such as low levels of carbon emissions and sustainability labels can increase the sales of food items in restaurants (Filimonau \& Krivcova, 2017; Gössling et al., 2011). However, Babakhani et al. (2020) found that carbon labels on restaurant menus attract little attention and that they are not perceived by patrons as motivating factors for ordering low emission menu items.

Rejecting a mutually exclusive understanding of egoism and altruism, the notion of selfish altruism (Miller, 2003) argues that tourists are willing to consume ethically but prefer this being paired with immediate and egoistic benefits. This basic idea is supported by research on the role of hedonism in ethical tourism (Malone et al., 2014). We assume that locally produced food is in alignment with the idea of selfish altruism as it is not only beneficial to the environment (e.g., due to a perceived shorter transport over fewer "food miles", see Brown et al., 2009) but at the same time it also conveys immediate ego-focused experiential and health-related benefits. This can be assumed because local food is potentially fresher, tastier, safer and has the added benefits of authenticity and association with specific terroirs (Mørkbak et al., 2010). In support of the assumed perceived health benefits, research suggests that labels making reference to domestic production increase consumers' perceptions of healthfulness (Devia et al., 2021).

Existing tourism and hospitality research also supports the interpretation of information indicating food localness as a hybrid self/other-benefit appeal. Local food can increase individuals' travel experience by allowing them to learn about local culture (Kim \& Eves, 2016) and thus can be linked to tourists' authenticity- and novelty-seeking (Sims, 2009). Other reasons for consuming local foods while on vacation include sensory appeals, prestige and perceived healthiness (Kim et al., 2009). Hospitality research also provides initial evidence that emphasising local origin can impact on consumers' food choices: Reporting information on food producers increased quality perceptions of food, aroused a sense of trust and led to positive evaluations of the whole dining experience (Campbell \& DiPietro, 2014).

Drawing from these considerations, we make a number of predictions with respect to the impact of different factual appeals on promoting more considerate food choices among tourists (see Figure 1). In general, disclosing some fact-related information should be better than none (see research on food package labels as in Newman et al., 2018). While egoistically anchored, placebo information stressing sensory pleasure (taste), without any disclosure of factual evidence, should be less impactful on tourists' food choices than evidence-based egoistic appeals (health benefits such as healthy nutritional composition) or selfish altruistic appeals (local origin such as fewer "food miles"). However, due to opposing effects, altruistic appeals (environmental benefits such as lower carbon footprint) should find it difficult to outperform such a placebo. In addition, we hypothesise that tourists are more strongly influenced by food-related information that is either predominantly egoistic or, in line with the idea of selfish altruism, combines egoistic and altruistic benefits, rather than by information pointing solely towards altruistic benefits. Consistent with Figure 1, we thus propose the following hypotheses:

H1: Compared to placebo information about freshness and taste, food consumption is higher when tourists are provided with factual information about health-benefits $(\mathrm{H} 1 \mathrm{a})$; not higher with factual information on environmental benefits ( $\mathrm{H} 1 \mathrm{~b})$; and higher with factual information on the food's local origin ( $\mathrm{H} 1 \mathrm{c})$. 


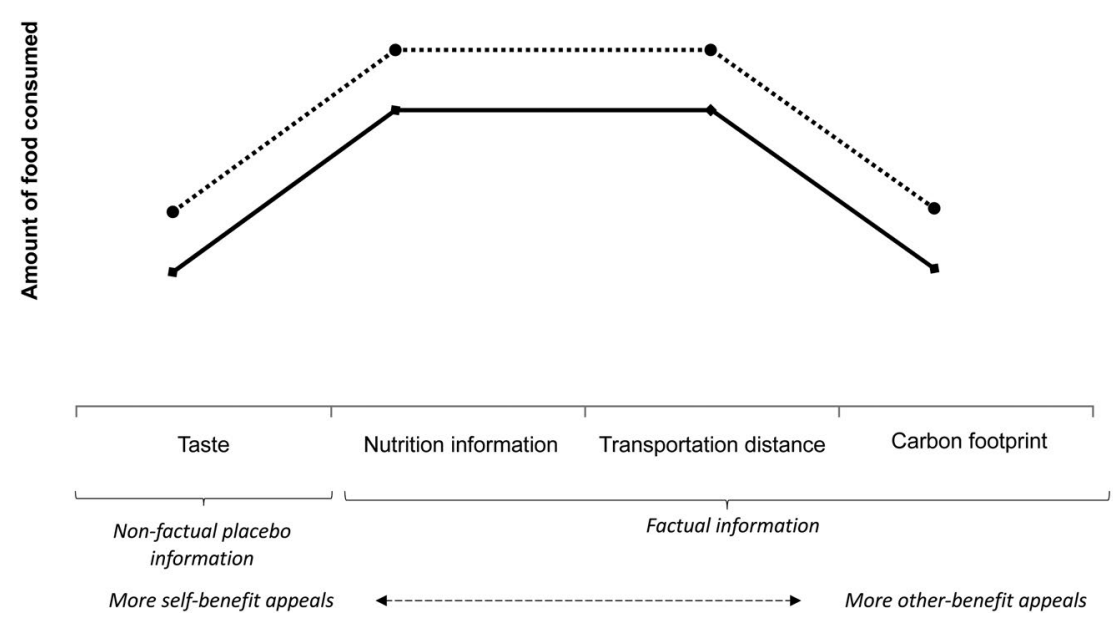

Figure 1. Predicted effects of factual appeals provided at hotel buffet table tents in light of the theoretical framework.

H2: Providing tourists with information about the health-related benefits $(\mathrm{H} 2 \mathrm{a})$ or the local origin $(\mathrm{H} 2 \mathrm{~b})$ of foods has a greater effect on the consumed amount of these foods than providing information on their environmental benefits.

\section{The role of appeal endorsement}

Endorsement of messages can be influential when the likelihood of detailed elaboration of the provided information is low due to the message having limited relevance to the consumer or the consumer being distracted (Petty \& Cacioppo, 1984). In this case, consumers may be persuaded by celebrity endorsers, non-celebrity endorsers or people endowed with high degrees of perceived credibility such as experts on the product category (Hanks et al., 2016). Celebrity endorsement has traditionally been considered a peripheral cue which works through system 1 processing. In system 1 processing consumers tend to pay more attention to cues that are unrelated to the issues and actual arguments at hand, and decisions may be made based on the physical attractiveness of the endorser (Van der Veen \& Song, 2014).

Expertise-based endorsement can have a different effect. If endorsers match well with the product, that is, if they are perceived to be knowledgeable on the product, evidence shows that consumers can be motivated to pay more attention to the conveyed issue-related arguments. This means that expertise-based endorsement can make it more likely that consumers elaborate the provided information through the argument-focused central route in system 2 processing (Lee \& Koo, 2016). Endorsement may be particularly relevant in hedonic tourism consumption where some authors argue that consumers tend to avoid effortful cognition (Lu $\&$ Chi, 2018). Existing research on endorsement in the hospitality and tourism industries supports the importance of endorsers' expertise (Kim et al., 2014), providing an indication that endorsement based on a good endorser-product match can be effective (Xu \& Pratt, 2018; Yang, 2018). Thus, endorsement by a competent person with high product involvement, such as an easy-to-implement hotel manager endorsement, can be expected to support effectiveness of persuasion of food-related messages at hotel buffets.

H3: Compared to providing information without endorsement, consumption is higher when the hotel general manager endorses the taste and freshness (placebo information, H3a), health-related benefits (H3b), environmental benefits $(\mathrm{H} 3 \mathrm{c})$ and the local origin $(\mathrm{H} 3 \mathrm{~d})$ of food. 


\section{Method}

\section{Design}

The study is based on a natural field experiment conducted in two Italian hotels adopting a $4 \times 2$ between-group experimental design (appeals $X$ endorsement). The experiment was conducted from July until September 2019 and data were collected for eight weeks. As the length of stay in both hotels is fixed at seven nights, the treatments were varied in a weekly rhythm and applied in randomised order, but all appeals were used in both hotels.

Treatments came in the form of point-of-consumption information on table tents trying to encourage consumption of different types of salad vegetables (tomato, lettuce) positioned at the salad buffet during lunch. Resulting overall actual consumption of salad vegetables was weighed on a daily basis. In addition, a short survey gathering information on tourists' perceived consumption from the salad buffet was handed out to a sample of 30 hotel guests at the end of each week (329 completed questionnaires obtained with a response rate of $69 \%$ ).

\section{Participants}

During the data collection period an average of 520 tourists stayed at each of the two hotels per night. They received a standard full board arrangement. The vast majority of tourists staying at the two hotels were domestic Italian (94\%); many of them were families with children resulting in a $30 \%$ share of non-adults among the total number of guests. Based on survey responses, $88 \%$ of adult tourists were aged between 31 and 60 and $80 \%$ indicated that their travel party consisted of more than two people. $85 \%$ indicated an annual income bracket between $30,000 €$ and $70,000 €$.

\section{Stimuli}

Applying Hardeman et al. (2000) classification of behavioural change research, this study applies an environmental manipulation at the point-of-purchase/point-of-consumption. All interventions except the placebo displayed factual information, and health and ecological information was predominantly numerical. We added an evaluative component to the objective information (green colour and emojis) to aid interpretation as existing literature indicates that this increases effectiveness in influencing consumer point-of-purchase/point-of-consumption food choices (Newman et al., 2018). Existing research also provides evidence that appeals that include pictorial or intuitive elements tends to be more impactful (Guthrie et al., 2015).

The information was delivered in writing on table tents at the hotel salad buffet table. The stimuli consisted of eight different table tents (4 appeals endorsed or non-endorsed) and were presented in a way to ensure visual attention. All the eight stimuli targeted lettuce and, in parallel, a constant placebo appeal (emphasising tastiness and freshness), was presented for tomato. Appeals were formulated in Italian and the English translation is given below:

- $\quad$ Placebo appeal - [P] ("Enjoy the tastiness and the freshness of our lettuce!") (Taste-focused and thus classified as hedonic self-benefit appeal);

- Health appeal $[\mathrm{H}]$ providing nutritional information ("Here you can find information about the nutritional values of our lettuce: For $100 \mathrm{gr}$ ( 1 portion) - Energy Kcal: $15 \mathrm{Kcal}$, Saturated fat: $0.01 \mathrm{gr} \odot$, Protein: $1.4 \mathrm{gr}$, Sugar: $0.8 \mathrm{gr}$, Salt: $0.02 \mathrm{gr} \odot$ " [please note the emojis; values for saturated fat and salt bold were given in green]) (classified as non-hedonic self-benefit appeal); 
- Environmental appeal [E] providing information on carbon footprint ("Here you can find information about the environmental impact of our lettuce: For $100 \mathrm{gr}$ ( 1 portion) -Carbon footprint: $0.043 \mathrm{Kg}$ per al $\mathrm{KM} \odot$ The carbon footprint refers to the $\mathrm{CO} 2$ emission attributable to the transportation of lettuce." [please note the emoji; value was given in bold and in green]) (classified as other-benefit appeal);

- Local appeal $[\mathrm{L}]$ providing information on the local origin ("Here you can find information about the provenance of our lettuce: Farm name, place, grown xx metres from the hotel, made in the region") (classified as both self-benefit and other-benefit appeal).

These four messages were also presented in an alternative version that included an endorsement by the hotels' GMs (with photo, name and position provided) [endP, endH, endE, endL]. Note that the hotels' patrons tend to be aware of the GMs as they introduce themselves personally on arrival day.

\section{Measures and variables}

Total consumption of the two salad buffet items lettuce and tomato was measured separately and daily at each hotel. This was achieved by subtracting the weight of food left over in the salad station at the end of the meal from the weight provided. Daily consumption of lettuce and tomato was normalised by the number of tourists at the hotel (available from hotel attendance records). Consistent with expected higher consumption of adults than children, consumption per person was calculated as daily consumption (in grams) divided by the sum of the number of adults (18years old or older) and half the number of children (between 3 and 17years old). Infants (2years old or younger) were ignored. Although results are similar if only adults are considered or if all people count equally, daily consumption is predicted with slightly higher accuracy with this weighting for adults (1), children (0.5) and infants (0).

In addition to measuring the consumption of vegetables, a short survey was administered on a sample of adult tourists at the end of each week. This included two key questions used to validate the results on actual consumption. The first was the percentage of vegetables the visitor ate out of the vegetables they took from the buffet. This assisted interpretation since the measurement of consumption is for practical reasons the amount taken from the buffet which might differ from the amount eaten (the difference being wastage). The second question asked tourists the extent to which they perceived they were influenced by the message. Possible responses were that they did not see the message, they saw it but were not influenced by it, they ate a little more vegetables or they ate a lot more. This question was used to validate that tourists saw the message and this had an influence on consumption (attention and manipulation check).

\section{Statistical analysis}

Daily consumption within each week varied but with no consistent pattern over days. Variation from week to week was considerably higher, with $88 \%$ of the variation in lettuce consumption explained by week (i.e., the treatments) at the two hotels. With variation within the week amounting to only $12 \%$ of the variation in lettuce consumption, analysis is performed on the consumption averaged across the seven days within each week. Analysing weekly averages rather than daily data is consistent with the randomisation in the experimental design and avoids a need to make unrealistic assumptions that daily observations from day to day are independent.

Regressions on weekly averages of consumption per person per lunch (as the dependent variable) included the following dummy variables $H, E$, $L$, endP, end $H$, endE and endL and hotel as independent variables. Hotel is a dummy variable taking the values of 0 for the first hotel and 1 for the second hotel. The three dummy variables $H, E$ and $L$ equal 1 if respectively the 
health, environmental or local message was applied. With the placebo message as a reference, the coefficients for these three variables therefore estimate the effects corresponding to hypotheses $\mathrm{H} 1 \mathrm{a}, \mathrm{H} 1 \mathrm{~b}$ and $\mathrm{H} 1 \mathrm{c}$. The four dummy variables endP, endH, endE and endL equal 1 if respectively the Placebo $(\mathrm{P})$, Health $(\mathrm{H})$, Environment $(\mathrm{E})$ or Local $(\mathrm{L})$ message was applied together with endorsement. Hence, with the presence of the variables $H, E$ and $L$ in the regression, the coefficients for the four variables endP, endH, endE and endL therefore estimate the effects corresponding to hypotheses $\mathrm{H} 3 \mathrm{a}, \mathrm{H} 3 \mathrm{~b}, \mathrm{H} 3 \mathrm{C}$ and $\mathrm{H} 3 \mathrm{~d}$.

For the purpose of validity tests, the above analysis was repeated on the average percentage of salad vegetables the survey of tourists reported they ate (out of those taken from the buffet). This analysis tested any bias due to messages increasing the amount of salad vegetables taken but not eaten. Moreover, responses to the survey question concerning how tourists were influenced by the messages were summarised and compared to differences in consumption across treatments. Finally, the significance of other factors on consumption were tested by including additional variables to the regression. These covariates included the proportion of tourists who were children and the proportion of salad vegetables tourists report they ate (out of the vegetables they took from the buffet).

\section{Results}

Results are presented in the following two sections: first the results on consumption of lettuce and tomato and second results of validation tests.

\section{Experimental results on salad buffet consumption}

Figure 2 displays average tourists' consumption for the 'targeted' vegetable lettuce and the 'non-targeted' vegetable tomato for the four messages (placebo, health, environment and local)

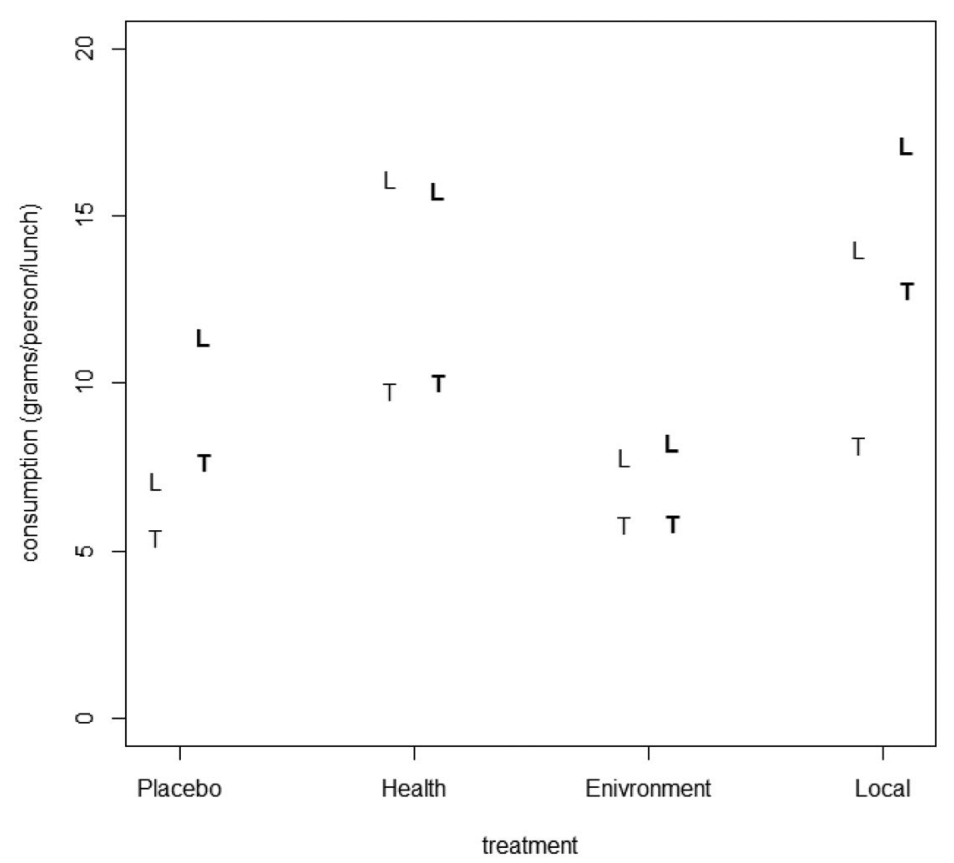

Figure 2. Tourists' average consumption of lettuce $(\mathrm{L})$ and tomato $(\mathrm{T})$ under four messages. Note: For each message, values in bold (and shifted to the right) are messages with endorsement. 
Table 1. Regression results predicting tourists' consumption (grams/person) of the lettuce (targeted) and tomato (non-targeted).

\begin{tabular}{|c|c|c|c|c|c|c|c|c|}
\hline & \multicolumn{4}{|c|}{ Lettuce (targeted) } & \multicolumn{4}{|c|}{ Tomato (non-targeted) } \\
\hline & B & SE & $\mathrm{t}$ & $\mathrm{p}$ & B & SE & $\mathrm{t}$ & $p$ \\
\hline Intercept & 4.72 & 0.96 & 4.90 & $.002^{* *}$ & 2.71 & 1.02 & 2.65 & $.033^{*}$ \\
\hline hotel & 4.74 & 0.64 & 7.37 & $.000^{* * *}$ & 5.43 & 0.68 & 7.97 & $.000^{* * *}$ \\
\hline $\mathrm{H}$ & 9.03 & 1.29 & 7.02 & $.000^{* * *}$ & 4.37 & 1.36 & 3.21 & $.015^{*}$ \\
\hline $\mathrm{E}$ & 0.71 & 1.29 & 0.55 & .599 & 0.37 & 1.36 & 0.27 & .792 \\
\hline L & 6.93 & 1.29 & 5.39 & $.001^{* *}$ & 2.72 & 1.36 & 2.00 & .086 \\
\hline endP & 4.28 & 1.29 & 3.33 & $.013^{*}$ & 2.24 & 1.36 & 1.64 & .145 \\
\hline endH & -0.39 & 1.29 & -0.30 & .773 & 0.23 & 1.36 & 0.17 & .870 \\
\hline endE & 0.42 & 1.29 & 0.33 & .751 & 0.04 & 1.36 & 0.03 & .979 \\
\hline endL & 3.08 & 1.29 & 2.39 & $.048^{*}$ & 4.66 & 1.36 & 3.42 & $.011^{*}$ \\
\hline
\end{tabular}

Notes: $\mathrm{H}, \mathrm{E}$ and $\mathrm{L}$ estimate effects relative to the placebo message (all unendorsed). endP, endH, endE and endL estimate the effect of the endorsed Placebo, Health, Environment, and Local messages relative to the respective unendorsed messages.

${ }^{* * *} p<.001$.

${ }^{* *} p<.01$.

${ }^{*} p<.05$.

both with endorsement (bold, to the right) and without endorsement (to the left). Table 1 summarises regressions predicting tourists' consumption (grams per person per lunch) of the two vegetables. For lettuce, which was the target of the messages, the intercept of 4.72 estimates the consumption of lettuce at Hotel 1 when the unendorsed placebo message is applied. Consumption at Hotel 2 is estimated to be 4.74 higher $(=9.46)$, so the average consumption with the unendorsed placebo message is 7.09 grams per person.

Relative to the baseline consumption using the unendorsed Placebo message, consumption of lettuce with the unendorsed Health message $(H)$ is significantly $(p<.001)$ higher by an estimated 9.03 grams per person per lunch. Thus, we find support for hypothesis H1a. Furthermore, this effect is not only statistically significant but large in practice: average consumption of lettuce with the Health message is more than double that of the Placebo message (see Figure 2: from 7.1 to 16.1 grams per person per lunch). While consumption is slightly higher (by 0.71) using the unendorsed Environmental message compared to the unendorsed Placebo message, this is not statistically significant $(\mathrm{p}=.599)$ consistent with $\mathrm{H} 1 \mathrm{~b}$. Hypothesis $\mathrm{H} 1 \mathrm{c}$ is supported as well, with significant $(\mathrm{p}=.001)$ evidence that consumption is higher with the unendorsed Local message than the unendorsed Placebo message by an estimated 6.93 grams per person per lunch. Thus, the Local message approximately doubles consumption of lettuce relative to the Placebo message (see Figure 2: from 7.1 to 14.0 grams per person per lunch).

The Health and Local messages also increase consumption relative to the Environmental message, which has similar consumption to the Placebo message (Figure 2). Formally comparing consumption with the unendorsed Environmental message, the Health message increases consumption by $8.3(p<.001)$ and the Local message increases consumption by $6.2(p=.002)$. Thus, these data support hypotheses $\mathrm{H} 2 \mathrm{a}$ and $\mathrm{H} 2 \mathrm{~b}$.

Endorsement of the Placebo message significantly $(p=.013)$ increases consumption by an estimated 4.28 grams per person per lunch, providing support for hypothesis H3a. Endorsing the Placebo message has an effect approximately half the effect of the unendorsed Health message. Endorsement of the Local message also significantly $(p=.048)$ increases consumption relative to the unendorsed Local message by an estimated 3.08 grams per person per lunch, providing support for hypothesis $\mathrm{H} 3 \mathrm{~d}$. However, we find insignificant evidence that endorsing the Health $(p=.773)$ or Environmental $(p=.751)$ messages increases consumption relative to the unendorsed Health and Environmental messages respectively. Therefore, we do not find support for hypotheses $\mathrm{H} 3 \mathrm{~b}$ and $\mathrm{H} 3 \mathrm{c}$. 
Although the messages specifically targeted lettuce, they also had effects on the consumption of tomato despite not being the target of the messages. Both the Health message (relative to the Placebo message, $p=.015$ ) and the endorsed Local message (relative to the unendorsed Local message, $p=.011$ ) significantly increased consumption of tomato. Despite the observable presence of an unintended side-effect, in general, the effects of messages on consumption are considerably smaller for the untargeted tomato than for the targeted lettuce.

\section{Validity tests}

The first validity test examines the possibility that our measurement of consumed vegetables is biased because not all vegetables taken from the buffet may be consumed by the tourists. The average proportion of vegetables eaten, as reported by surveyed tourists, was $86 \%$. This suggests wastage (vegetables taken but not eaten) are not material. Table 2 provides results of the regression predicting the average amount of vegetables that tourists report they ate (out of the vegetables taken). This did not vary significantly $(p>.1)$ between treatments (see Table 2$)$, although there was evidence $(p=.026)$ that the proportion of vegetables eaten was $2 \%$ lower at Hotel 2 compared to Hotel 1. Thus, we find no evidence the messages induced tourists to take more vegetables from the buffet without consuming them. Hence, although our measurement of consumption is the weight taken (weight supplied minus weight left over after the meal), our results for vegetables taken (Table 1) appear to be relevant for the amount of vegetables eaten as well.

The second validity test examines the possible causal links between the messages and consumption by examining visitor responses to a survey question about whether they were influenced by the message. Figure 3 shows the distribution of responses; in each case the majority of tourists noticed the information but reported it had no effect on them. Only the Health and Local messages received more substantial shares of responses indicating that tourists ate $a$ little more vegetables due to the message. These were also the only two messages receiving responses from tourists indicating they ate a lot more vegetables due to the message. The proportion of tourists indicating that the message had a positive effect (ate a little or a lot more vegetables) ranged from only $5 \%$ for the unendorsed Placebo message to $41 \%$ for the endorsed Local message. Compared to the Placebo message, the proportion of sampled tourists who indicated they ate (a little or a lot) more vegetables based on the message was significantly higher for the Health $(p=.013)$ and Local $(p=.036)$ messages, but endorsement did not have significant ( $p>.05$ ) effects for any of the four messages.

The trend in Figure 3 is similar to the trend in Figure 2 of actual consumption, providing validity to the causal link that the messages influenced consumption. In particular, the Health

Table 2. Regression results predicting the proportion of vegetables eaten (from survey of tourists).

\begin{tabular}{|c|c|c|c|c|}
\hline & \multicolumn{4}{|c|}{ Vegetables eaten } \\
\hline & B & SE & $t$ & $p$ \\
\hline Intercept & 0.85 & 0.01 & 65.40 & $0.000^{* * *}$ \\
\hline Hotel & -0.02 & 0.01 & -2.82 & $0.026^{*}$ \\
\hline $\mathrm{H}$ & 0.02 & 0.02 & 1.36 & 0.216 \\
\hline $\mathrm{E}$ & 0.03 & 0.02 & 1.75 & 0.124 \\
\hline L & 0.03 & 0.02 & 1.77 & 0.120 \\
\hline endP & 0.02 & 0.02 & 0.88 & 0.411 \\
\hline endH & -0.03 & 0.02 & -1.61 & 0.153 \\
\hline endE & -0.01 & 0.02 & -0.34 & 0.743 \\
\hline endL & 0.00 & 0.02 & -0.12 & 0.905 \\
\hline
\end{tabular}

${ }^{* * *} p<.001$

${ }^{* *} p<.01$

${ }^{*} p<.05$. 


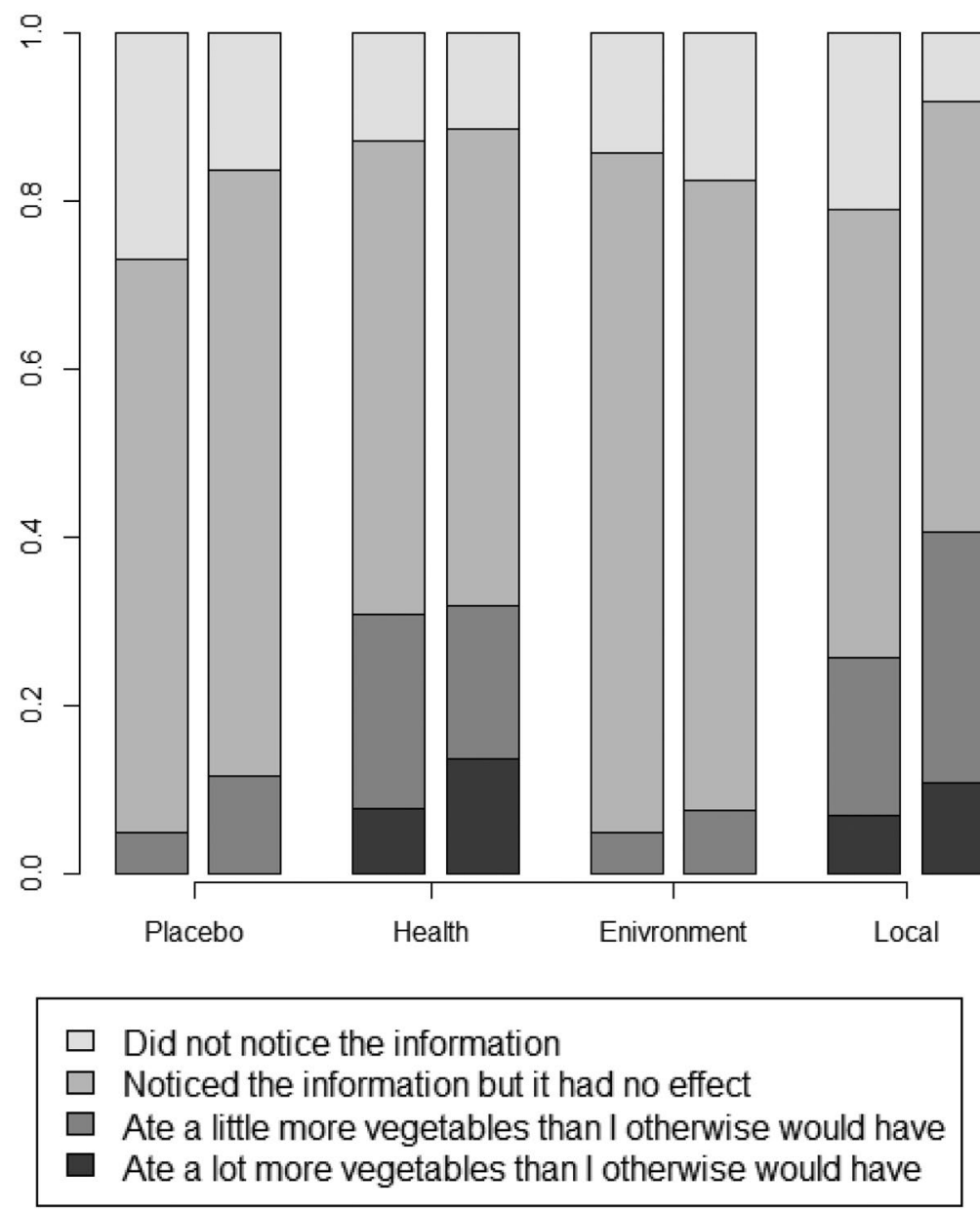

Figure 3. Distribution of visitor responses to the survey question concerning the influence of the four endorsed (right) and unendorsed (left) messages.

and Local messages that created the largest change in actual consumption are also the messages that had the largest effect on tourists' perceptions of the effect of the messages on their behaviour. For example, the average consumption of lettuce with the endorsed Local message was 17.1 grams per person per lunch, almost two and a half times the consumption with the unendorsed placebo message. This large increase in consumption was obtained with only $10.8 \%$ of tourists indicating they ate a lot more, and $29.7 \%$ of tourists indicating they ate a little more (compared to $0 \%$ and $4.9 \%$ respectively for the unendorsed Placebo message). This suggests many tourists either are not consciously aware of the influence the messages have on them or they report they have no influence due to social-desirability bias (they do not wish to admit messages have an impact). A similar trend is apparent for the endorsed and unendorsed Placebo message.

Finally, a third validity test included the proportion of tourists who were children as a covariate in the model in Table 1 . This variable was not statistically significant for lettuce $(p=.073)$ or tomato $(p=.234)$ and consequently the estimated effects of the treatments are similar to those reported in Table 1. Similarly, including the self-reported proportion of vegetables eaten by tourists (i.e., proportion of vegetables eaten among those taken) as an extra covariate in the regression were insignificant for lettuce $(p=.162)$ and tomato $(p=.623)$. Alternatively, 
repeating the regression after multiplying the consumption values by the self-reported percentage of vegetables eaten as the dependent variable produced similar regression results.

\section{Discussion}

The results of this research entail that factual self-benefit appeals as well as hybrid self/ other-benefit appeals positioned as table-tents at hotel buffets had statistically significant and large practical effects on tourists' actual salad vegetable consumption. The test results support the superiority of factual information on foods' healthiness (nutritional information, $\mathrm{H} 1 \mathrm{a}$ ) and foods' local origin (distance of transportation, H1c) over non-factual placebo information on taste. Instead, and in line with $\mathrm{H} 1 \mathrm{~b}$, ecological information on foods' carbon footprint did not outperform the placebo information. As a consequence and in line with $\mathrm{H} 2 \mathrm{a}$ and $\mathrm{H} 2 \mathrm{~b}$, giving nutritional facts (self-benefit) or information on the distance of transportation (self/other-benefit) has a greater impact on tourists' food consumption than displaying information on carbon footprint (other-benefit). Endorsement of appeals through the hotels' general managers showed mixed results: It had an effect on the local origin (H3d supported) and placebo appeals stressing tastiness (H3a supported), but was unable to significantly enhance the persuasiveness of health appeals (H3b not supported) and ecological appeals (H3c not supported).

Tourists seem to care more about their own health and their sensory pleasure, than about everyone's environment. Indeed, the findings illustrate that self-benefit appeals and hybrid self/ other-benefit appeals have an effect on food choices of tourists on hotel buffets but other-benefit appeals do not. These findings substantiate the idea that tourism consumption is primarily egoistically driven and that altruism appears in a proximate fashion as 'selfish altruism' (Miller, 2003), where tourists appear willing to consume ethically, but prefer this being paired with egoistic benefits (Baker et al., 2014), such as health advantages and sensory pleasure. This ego-orientated food consumption behaviour is aligned with the motivational features observed in the tourism context where people aim at pursuing pleasant and memorable experiences (Mitas \& Bastiaansen, 2018).

The results also match recent findings in sustainability marketing regarding persuasion for more sustainable tourism consumption: The chances of successful persuasion of tourists rise if appeals combine communicating ecological advantages with individual gains in mixed self/ other-centred messages (Font \& McCabe, 2017; Hardeman et al., 2017; Villarino \& Font, 2015). However, contrasting some of the existing literature, the observed effectiveness of health-related facts on nutritional features indicates that egoistic benefits beyond hedonic and emotional elements may be persuasive.

This research contributes to the literature on consumer persuasion towards more considerate food choices. There are implications regarding how interventions can be framed as well as when/where they can be made. The findings also indicate that factual messages (with an evaluative element) can be effective in influencing food choices not only in everyday-purchase situations (Newman et al., 2018) but also in a tourism setting. This finding is in contrast with some studies doubting the effectiveness of rational information (e.g., Wehrli et al., 2017). For instance, rational information on nutritional contents appears to be a promising strategy to encourage healthier eating on holiday. Finally, the findings are also in accordance with earlier evidence that point-of-consumption/point-of-purchase messages can influence tourists' food choices (Cozzio et al., 2020; Dolnicar et al., 2020). It should be noted though, that the popular buffet-style meal serving accentuates psychological factors such as the fear of missing out and people's laziness to visit the buffet more than once (Dolnicar \& Juvan, 2019) which might favourably influence the persuasiveness of point-of-consumption interventions. Furthermore, as the behaviour of others influences people (Kalafatis et al., 1999), observing food choices of other tourists at the buffet might also impact personal food choices. Moreover, it is reasonable to 
assume that domestic Italian guests (which accounted for $94 \%$ of all tourists) may have a culturally-rooted high regard of Italian origin in food, thus particularly appreciating the local provenance appeal.

In terms of endorsement, this research finds indications that expertise-based endorsement can have an effect on strengthening persuasion as expected by the product-endorser match-up hypothesis (Lee \& Koo, 2016). Hotel general managers, who were used as endorsers in this study, match the tourism and food categories. They are arguably competent to speak about taste and local purchasing of buffet items (where endorsement made a significant difference), but perhaps slightly less so about their nutritional and ecological features (where no statistically significant effect of endorsement was observed). Hence, the obtained mixed findings indicate that more differentiation is required: In addition to the product-endorser match, trustworthiness and expertise in regards to the specific persuasive message appear as a critical dimension in understanding effectiveness of endorsement.

The effective appeals had a demonstrated effect on tourists' consumption of the targeted vegetable lettuce, but they also had an effect on the consumption of tomato, which throughout the whole experiment remained under the placebo condition. This supports the existence of a potential halo effect, a cognitive bias that makes it difficult to evaluate each appeal in isolation (Nicolau et al., 2020). In line with prior findings where, for instance, kosher labelling amplifies the perception of menu item healthfulness when presented with nutritional information (Jeong \&Jang, 2020), the halo effect observed in this study is congruent with the initial aim of the intervention that is promoting virtuous food choices among tourists.

It is interesting to compare the collected data on actual consumption with tourists' perceptions on the influence of the appeals. Relatively few tourists indicate they are influenced by the messages yet the effects on consumption are relatively large. This suggests either a few tourists are influenced to consume a lot more or tourists under-report or under-estimate the extent to which they are influenced by the messages. There are differences in degree of the effects but the same messages appear to be impactful on both actual consumption and reported consumption, which indicates that working with reported consumption might reach similar qualitative conclusions. Given the quantitative differences between stated and actual consumption, we conclude tourists are influenced by the health and local messages to consume more but they are unaware of the full extent these messages have on them. This finding reinforces that measuring actual consumption is important, but at the same time further research is encouraged to compare stated with actual food consumption of tourists to complement the work done on the attitude-behaviour gap (Hibbert et al., 2013).

\section{Conclusion}

Despite the importance of tourists' food choices for sustainable development of the tourism industry and for the health of tourists, studies on the relationship between providing information on experiential benefits, health benefits and environmental benefits, and tourists' food choices are lacking. To close this gap, this paper presented an unobtrusive randomised field experiment to analyse the effect of different interventions presenting factual information on increasing the consumption of salad vegetables among tourists at hotel buffets. With its findings, the paper makes several substantial theoretical contributions.

First, this is the first research testing the impact of presenting environmental facts at the point-of-consumption/point-of-purchase (such as carbon footprints) on the food consumption of tourists. There have been a few studies in restaurants obtaining mixed findings but none has focussed on tourism consumption specifically. Second, this is also the first research directly testing the effect of factual health information (nutritional information) on tourists' food choices. It is one of very few attempts to investigate the importance of healthy eating while on holiday; 
and, more generally, also a rare attempt of linking health and tourism consumption. Third, this is also the first study that quantifies the effects of offering different types of factual information (such as nutrition information, carbon footprints and distance of transportation) on tourists' food choices in hotels; and thus it is the first study that allows establishing the relative effectiveness of these point-of-consumption/point-of-purchase interventions in a comparative manner. The study finds that appeals that present nutritional facts and information on "food miles" are superior to appeals stressing carbon footprint.

Fourth, findings on endorsement are in line with the basic idea that expertise and credibility of endorsers drive their effectiveness in supporting persuasion attempts in tourism consumption (Yang, 2018). However, the observed varying effectiveness of endorsement depending on the underlying message indicates a need to expand the limited research on expertise-based endorsement in persuasive communication in tourism, and other product areas. Fifth, this study contributes to the understanding of the role of altruism vs egoism in the tourism context. By showing that tourists are more strongly influenced by nutritional (health) information and information on the distance of transportation (local origin) when choosing their food, this study provides evidence that pure altruism is rare in tourism consumption. Findings rather support the notion of "selfish altruism" (Miller, 2003). The obtained findings are in line with the idea that self-benefits and hybrid self/other-benefits outperform mere other-benefits in tourism consumption.

Based on these findings, a number of practical implications for hotel managers and other hospitality providers serving food to tourists can be outlined. The study indicates that it is promising for hotel managers to include information about the nutritional facts and "food miles" to induce tourists to consume healthier, more eco-friendly and also more sensorily pleasing food. It seems less promising for hotel managers to provide facts on the carbon impact of food. In sum, interventions that are also (but not necessarily exclusively) relatable with individual benefits for tourists are more practically relevant. A simple and uncomplicated endorsement of such messages through a hotel general manager can increase the effect, in particular for messages that stress the local origin of food.

Despite achieving important findings and making relevant contributions, this study also has its limitations. One limitation is linked to the measuring of average daily consumption rather than individual consumption of a single tourist. While we obtained precious behavioural data, the applied design does not allow to link behaviour to specific attitudes of individuals. Moreover, due to practical limitations in the unobtrusive environment, we only applied one type of endorsement out of many available (see e.g., Yang, 2018), and did not investigate consumer perceptions of this particular endorsement. Hence, caution is required if generalising to other types of endorsement. As interventions have only been applied to one type of food (vegetables), findings cannot necessarily be generalised to other types of food. Similarly, caution is required with any generalisations to other dining settings. Albeit some limitations, this research made important steps towards understanding how tourists can be persuaded at the point-of-consumption/point-of-purchase to make virtuous food choices. Future research can build on these findings by not only investigating the role of endorsement on tourists' food choices in more depth but also varying the form of presentation of information even further (comparing objective and evaluative information, and comparing different types of evaluative information). Future research should also collect more data to investigate the observed indirect effect (or halo effect) to non-targeted food items, including examining its magnitude and its drivers. Research on this topic seems very much in its infancy (see Medina, 2021).

\section{Disclosure statement}

No potential conflict of interest was reported by the authors. 


\section{ORCID}

Claudia Cozzio (iD http://orcid.org/0000-0002-5533-1638

\section{References}

Babakhani, N., Lee, A., \& Dolnicar, S. (2020). Carbon labels on restaurant menus: do people pay attention to them? Journal of Sustainable Tourism, 28(1), 51-68. https://doi.org/10.1080/09669582.2019.1670187

Baker, M. A., Davis, E. A., \& Weaver, P. A. (2014). Eco-friendly attitudes, barriers to participation, and differences in behavior at green hotels. Cornell Hospitality Quarterly, 55(1), 89-99. https://doi.org/10.1177/1938965513504483

Bendapudi, N., Singh, S. N., \& Bendapudi, V. (1996). Enhancing helping behavior: An integrative framework for promotion planning. Journal of Marketing, 60(3), 33-49. https://doi.org/10.1177/002224299606000303

Bertella, G. (2020). Re-thinking sustainability and food in tourism. Annals of Tourism Research, 84, 103005.

Bialkova, S., \& van Trijp, H. C. (2011). An efficient methodology for assessing attention to and effect of nutrition information displayed front-of-pack. Food Quality and Preference, 22(6), 592-601. https://doi.org/10.1016/j.foodqual.2011.03.010

Brown, E., Dury, S., \& Holdsworth, M. (2009). Motivations of consumers that use local, organic fruit and vegetable box schemes in Central England and Southern France. Appetite, 53(2), 183-188. https://doi.org/10.1016/j.appet.2009.06.006

Campbell, J. M., \& DiPietro, R. B. (2014). Sign of the times: Testing consumer response to local food signage within a casual dining restaurant. Journal of Retailing and Consumer Services, 21(5), 812-823. https://doi. org/10.1016/j.jretconser.2014.06.010

Chambault, S. T. (2016). Explicit methods to capture consumers' responses to packaging. In P. Burgess (Ed.), Integrating the packaging and product experience in food and beverage (pp. 139-159). Woodhead Publishing.

Chang, R. C. (2017). The influence of attitudes towards healthy eating on food consumption when travelling. Current Issues in Tourism, 20(4), 369-390. https://doi.org/10.1080/13683500.2014.890579

Choi, D., \& Lee, H. K. (2020). Beneficiary Foci Types and Performance Appeals in Green Advertising. Sustainability, 12(15), 6251. https://doi.org/10.3390/su12156251

Clark, J. E. (1998). Taste and flavour: their importance in food choice and acceptance. Proceedings of the Nutrition Society, 57(4), 639-643. https://doi.org/10.1079/PNS19980093

Comte, A. (1851). Système de politique positive. Mathias.

Cozzio, C., Volgger, M., Taplin, R., \& Woodside, A. G. (2020). Nurturing tourists' ethical food consumption: Testing the persuasive strengths of alternative messages in a natural hotel setting. Journal of Business Research, 117, 268-279. https://doi.org/10.1016/j.jbusres.2020.05.050

Devia, G., Forli, S., Vidal, L., Curutchet, M. R., \& Ares, G. (2021). References to home-made and natural foods on the labels of ultra-processed products increase healthfulness perception and purchase intention: Insights for policy making. Food Quality and Preference, 88, 104110. https://doi.org/10.1016/j.foodqual.2020.104110

Dolnicar, S., \& Juvan, E. (2019). Drivers of plate waste. Annals of Tourism Research, 78, 102731. https://doi. org/10.1016/j.annals.2019.05.008

Dolnicar, S., Juvan, E., \& Grün, B. (2020). Reducing the plate waste of families at hotel buffets-A quasi-experimental field study. Tourism Management, 80, 104103. https://doi.org/10.1016/j.tourman.2020.104103

Fennell, D. (2006). Evolution in tourism: The theory of reciprocal altruism and tourist-host interactions. Current Issues in Tourism, 9(2), 105-124. https://doi.org/10.1080/13683500608668241

Filimonau, V., \& Krivcova, M. (2017). Restaurant menu design and more responsible consumer food choice: An exploratory study of managerial perceptions. Journal of Cleaner Production, 143, 516-527. https://doi.org/10.1016/j. jclepro.2016.12.080

Filimonau, V., Lemmer, C., Marshall, D., \& Bejjani, G. (2017). Nudging'as an architect of more responsible consumer choice in food service provision: The role of restaurant menu design. Journal of Cleaner Production, 144, 161-170. https://doi.org/10.1016/j.jclepro.2017.01.010

Font, X., \& McCabe, S. (2017). Sustainability and marketing in tourism: Its contexts, paradoxes, approaches, challenges and potential. Journal of Sustainable Tourism, 25(7), 869-883. https://doi.org/10.1080/09669582.2017.13 01721

Gao, Y., Wu, L., Shin, J., \& Mattila, A. S. (2020). Visual design, message content, and benefit type: The case of a cause-related marketing campaign. Journal of Hospitality \& Tourism Research, 44(5), 761-779. https://doi. org/10.1177/1096348020911444

Gössling, S., Garrod, B., Aall, C., Hille, J., \& Peeters, P. (2011). Food management in tourism: Reducing tourism's carbon 'foodprint. Tourism Management, 32(3), 534-543. https://doi.org/10.1016/j.tourman.2010.04.006

Green, T., \& Peloza, J. (2014). Finding the right shade of green: The effect of advertising appeal type on environmentally friendly consumption. Journal of Advertising, 43(2), 128-141. https://doi.org/10.1080/00913367.2013.8 34805 
Guha, A., Biswas, A., Grewal, D., Bhowmick, S., \& Nordfält, J. (2018). An empirical analysis of the joint effects of shoppers' goals and attribute display on shoppers' evaluations. Journal of Marketing, 82(3), 142-156. https:// doi.org/10.1509/jm.16.0247

Guthrie, J., Mancino, L., \& Lin, C. T. J. (2015). Nudging consumers toward better food choices: Policy approaches to changing food consumption behaviors. Psychology \& Marketing, 32(5), 501-511. https://doi.org/10.1002/ mar.20795

Hanks, L., Zhang, L., \& McGinley, S. (2016). Unconditioned superstition and sports bar fans. Journal of Hospitality Marketing \& Management, 25(1), 113-131. https://doi.org/10.1080/19368623.2014.987417

Hardeman, G., Font, X., \& Nawijn, J. (2017). The power of persuasive communication to influence sustainable holiday choices: Appealing to self-benefits and norms. Tourism Management, 59, 484-493. https://doi.org/10.1016/j. tourman.2016.09.011

Hardeman, W., Griffin, S., Johnson, M., Kinmonth, A. L., \& Warehman, N. J. (2000). Interventions to pre-vent weight gain: a systematic review of psychological models and behaviour change methods. International Journal of Obesity, 24, 131-143. https://doi.org/10.1038/sj.ijo.0801100

Hibbert, J. F., Dickinson, J. E., Gössling, S., \& Curtin, S. (2013). Identity and tourism mobility: an exploration of the attitude-behaviour gap. Journal of Sustainable Tourism, 21(7), 999-1016. https://doi.org/10.1080/09669582.201 3.826232

Hosany, S., \& Gilbert, D. (2010). Measuring tourists' emotional experiences toward hedonic holiday destinations. Journal of Travel Research, 49(4), 513-526. https://doi.org/10.1177/0047287509349267

Howlett, E. A., Burton, S., Bates, K., \& Huggins, K. (2009). Coming to a restaurant near you? Potential consumer responses to nutrition information disclosure on menus. Journal of Consumer Research, 36(3), 494-503. https:// doi.org/10.1086/598799

Hwang, J., \& Lorenzen, C. L. (2008). Effective nutrition labeling of restaurant menu and pricing of healthy menu. Journal of Foodservice, 19(5), 270-276. https://doi.org/10.1111/j.1748-0159.2008.00108.x

Inman, J. J., \& Winer, R. S. (1998). Where the rubber meets the road: A model of in-store consumer decision-making. Marketing Science Institute Working Paper, 1, 98-122.

Jäger, A. K., \& Weber, A. (2020). Can you believe it? The effects of benefit type versus construal level on advertisement credibility and purchase intention for organic food. Journal of Cleaner Production, 257, 120543. https:// doi.org/10.1016/j.jclepro.2020.120543

Jeong, E., \& Jang, S. (2020). Kosher labelling in restaurants: Examining the healthy halo effect. Journal of Foodservice Business Research, 23(1), 46-56. https://doi.org/10.1080/15378020.2019.1671121

Johnston, J., \& Baumann, S. (2014). Foodie Politics: This is one delicious revolution!. In J. Johnston \& S. Baumann (Eds.), Foodies: democracy and distinction in the gourmet foodscape (pp. 112-151). Routledge.

Kahneman, D. (2011). Thinking, fast and slow. Farrar, Straus and Giroux.

Kalafatis, S. P., Pollard, M., East, R., \& Tsogas, M. H. (1999). Green marketing and Ajzen's theory of planned behaviour: a cross-market examination. Journal of Consumer Marketing, 16(5), 441-460. https://doi. org/10.1108/07363769910289550

Kareklas, I., Carlson, J. R., \& Muehling, D. D. (2014). I eat organic for my benefit and yours": Egoistic and altruistic considerations for purchasing organic food and their implications for advertising strategists. Journal of Advertising, 43(1), 18-32. https://doi.org/10.1080/00913367.2013.799450

Kergoat, M., Meyer, T., \& Legal, J. B. (2019). Influence of "health" versus "commercial" physical activity message on snacking behavior. Journal of Consumer Marketing, 37(2), 170-179. https://doi.org/10.1108/ JCM-07-2018-2765

Kim, Y. G., \& Eves, A. (2012). Construction and validation of a scale to measure tourist motivation to consume local food. Tourism Management, 33(6), 1458-1467. https://doi.org/10.1016/j.tourman.2012.01.015

Kim, Y. G., \& Eves, A. (2016). Measurement equivalence of an instrument measuring motivation to consume local food: A cross-cultural examination across British and Korean. Journal of Hospitality \& Tourism Research, 40(5), 634-652. https://doi.org/10.1177/1096348013515922

Kim, Y. G., Eves, A., \& Scarles, C. (2009). Building a model of local food consumption on trips and holidays: A grounded theory approach. International Journal of Hospitality Management, 28(3), 423-431. https://doi. org/10.1016/j.ijhm.2008.11.005

Kim, S. S., Lee, J., \& Prideaux, B. (2014). Effect of celebrity endorsement on tourists' perception of corporate image, corporate credibility and corporate loyalty. International Journal of Hospitality Management, 37, 131-145. https:// doi.org/10.1016/j.jihm.2013.11.003

Lee, Y., \& Koo, J. (2016). Can a celebrity serve as an issue-relevant argument in the elaboration likelihood model? Psychology \& Marketing, 33(3), 195-208. https://doi.org/10.1002/mar.20865

Lo, A., King, B., \& Mackenzie, M. (2017). Restaurant customers' attitude toward sustainability and nutritional menu labels. Journal of Hospitality Marketing \& Management, 26(8), 846-867. https://doi.org/10.1080/19368623.2017.1 326865

Lockstone-Binney, L., Holmes, K., Smith, K., \& Baum, T. (2010). Volunteers and volunteering in leisure: Social science perspectives. Leisure Studies, 29(4), 435-455. https://doi.org/10.1080/02614367.2010.527357 
Lu, L., \& Chi, C. G. Q. (2018). Examining diners' decision-making of local food purchase: The role of menu stimuli and involvement. International Journal of Hospitality Management, 69, 113-123. https://doi.org/10.1016/j. ijhm.2017.10.012

Malone, S., McCabe, S., \& Smith, A. P. (2014). The role of hedonism in ethical tourism. Annals of Tourism Research, 44, 241-254. https://doi.org/10.1016/j.annals.2013.10.005

Medina, P. C. (2021). Side effects of nudging: Evidence from a randomized intervention in the credit card market. The Review of Financial Studies, 34(5), 2580-2607. https://doi.org/10.1093/rfs/hhaa108

Miller, G. A. (2003). Consumerism in sustainable tourism: A survey of UK consumers. Journal of Sustainable Tourism, 11(1), 17-39. https://doi.org/10.1080/09669580308667191

Milliron, B. J., Woolf, K., \& Appelhans, B. M. (2012). A point-of-purchase intervention featuring in-person supermarket education affects healthful food purchases. Journal of Nutrition Education and Behavior, 44(3), $225-232$. https://doi.org/10.1016/j.jneb.2011.05.016

Mitas, O., \& Bastiaansen, M. (2018). Novelty: A mechanism of tourists' enjoyment. Annals of Tourism Research, 72, 98-108. https://doi.org/10.1016/j.annals.2018.07.002

Moorman, C., \& Matulich, E. (1993). A model of consumers' preventive health behaviors: The role of health motivation and health ability. Journal of Consumer Research, 20(2), 208-228. https://doi.org/10.1086/209344

Mørkbak, M. R., Christensen, T., \& Gyrd-Hansen, D. (2010). Consumer preferences for safety characteristics in pork. British Food Journal, 112(7), 775-791. https://doi.org/10.1108/00070701011058299

Moskwa, E., Higgins-Desbiolles, F., \& Gifford, S. (2015). Sustainability through food and conversation: The role of an entrepreneurial restaurateur in fostering engagement with sustainable development issues. Journal of Sustainable Tourism, 23(1), 126-145. https://doi.org/10.1080/09669582.2014.940046

Newman, C. L., Burton, S., Andrews, J. C., Netemeyer, R. G., \& Kees, J. (2018). Marketers' use of alternative front-ofpackage nutrition symbols: An examination of effects on product evaluations. Journal of the Academy of Marketing Science, 46(3), 453-476. https://doi.org/10.1007/s11747-017-0568-z

Newman, C. L., Howlett, E., \& Burton, S. (2016). Effects of objective and evaluative front-of-package cues on food evaluation and choice: The moderating influence of comparative and noncomparative processing contexts. Journal of Consumer Research, 42(5), 749-766. https://doi.org/10.1093/jcr/ucv050

Nicolau, J. L., Mellinas, J. P., \& Martín-Fuentes, E. (2020). The halo effect: A longitudinal approach. Annals of Tourism Research, 83, 102938. https://doi.org/10.1016/j.annals.2020.102938

Nobrega, L., Ares, G., \& Deliza, R. (2020). Are nutritional warnings more efficient than claims in shaping consumers' healthfulness perception? Food Quality and Preference, 79, 103749. https://doi.org/10.1016/j.foodqual.2019.103749

Paraskevaidis, P., \& Andriotis, K. (2017). Altruism in tourism: Social exchange theory vs altruistic surplus phenomenon in host volunteering. Annals of Tourism Research, 62, 26-37. https://doi.org/10.1016/ j.annals.2016.11.002

Petty, R. E., \& Cacioppo, J. T. (1984). Source factors and the elaboration likelihood model of persuasion. In T. C. Kinnear (Ed.), Advances in consumer research (Vol. 11, pp. 668-672). Association for Consumer Research.

Rizzi, F., Annunziata, E., Contini, M., \& Frey, M. (2020). On the effect of exposure to information and self-benefit appeals on consumer's intention to perform pro-environmental behaviours: $A$ focus on energy conservation behaviours. Journal of Cleaner Production, 270, 122039. https://doi.org/10.1016/j.jclepro.2020.122039

Sanjari, S. S., Jahn, S., \& Boztug, Y. (2017). Dual-process theory and consumer response to front-of-package nutrition label formats. Nutrition Reviews, 75(11), 871-882. https://doi.org/10.1093/nutrit/nux043

Shafieizadeh, K., \& Tao, C. W. W. (2020). How does a menu's information about local food affect restaurant selection? The roles of corporate social responsibility, transparency, and trust. Journal of Hospitality and Tourism Management, 43, 232-240. https://doi.org/10.1016/j.jhtm.2020.04.007

Sims, R. (2009). Food, place and authenticity: local food and the sustainable tourism experience. Journal of Sustainable Tourism, 17(3), 321-336. https://doi.org/10.1080/09669580802359293

Sun, Y. H. C. (2013). Menu nutrition labels' effects on customers' attitudes toward menu and restaurant dining intentions-The moderating role of psychosocial factors. Journal of Foodservice Business Research, 16(2), $139-154$. https://doi.org/10.1080/15378020.2013.782234

Torres, R., \& Skillicorn, P. (2004). Montezuma's revenge: How sanitation concerns may injure Mexico's tourist industry. Cornell Hotel and Restaurant Administration Quarterly, 45(2), 132-144. https://doi. org/10.1177/0010880404263367

Trivers, R. (1985). Social evolution. Benjamin/Cummings.

Van der Veen, R., \& Song, H. (2014). Impact of the perceived image of celebrity endorsers on tourists' intentions to visit. Journal of Travel Research, 53(2), 211-224. https://doi.org/10.1177/0047287513496473

Van Herpen, E., \& Van Trijp, H. C. (2011). Front-of-pack nutrition labels. Their effect on attention and choices when consumers have varying goals and time constraints. Appetite, 57(1), 148-160. https://doi.org/10.1016/j.appet.2011.04.011

Villarino, J., \& Font, X. (2015). Sustainability marketing myopia: The lack of persuasiveness in sustainability communication. Journal of Vacation Marketing, 21(4), 326-335. https://doi.org/10.1177/1356766715589428 
Visser, M., Gattol, V., \& Helm, R. V. D. (2015). Communicating sustainable shoes to mainstream consumers: the impact of advertisement design on buying intention. Sustainability, 7(7), 8420-8436. https://doi.org/10.3390/ su7078420

Wansink, B., Painter, J., \& Ittersum, K. V. (2001). Descriptive menu labels' effect on sales. Cornell Hotel and Restaurant Administration Quarterly, 42(6), 68-72.

Wehrli, R., Priskin, J., Demarmels, S., Schaffner, D., Schwarz, J., Truniger, F., \& Stettler, J. (2017). How to communicate sustainable tourism products to customers: Results from a choice experiment. Current Issues in Tourism, 20(13), 1375-1394. https://doi.org/10.1080/13683500.2014.987732

White, K., \& Peloza, J. (2009). Self-benefit versus other-benefit marketing appeals: Their effectiveness in generating charitable support. Journal of Marketing, 73(4), 109-124. https://doi.org/10.1509/jmkg.73.4.109

White, K., \& Simpson, B. (2013). When do (and don't) normative appeals influence sustainable consumer behaviors? Journal of Marketing, 77(2), 78-95. https://doi.org/10.1509/jm.11.0278

Wilson, D. S. (2015). Does altruism exist? Culture, genes and the welfare of others. Yale University Press.

Xu, X., \& Pratt, S. (2018). Social media influencers as endorsers to promote travel destinations: an application of self-congruence theory to the Chinese Generation Y. Journal of Travel \& Tourism Marketing, 35(7), 958-972.

Yadav, R. (2016). Altruistic or egoistic: Which value promotes organic food consumption among young consumers? A study in the context of a developing nation. Journal of Retailing and Consumer Services, 33, 92-97. https:// doi.org/10.1016/j.jretconser.2016.08.008

Yang, W. (2018). Star power: the evolution of celebrity endorsement research. International Journal of Contemporary Hospitality Management, 30(1), 389-415. https://doi.org/10.1108/IJCHM-09-2016-0543 